\title{
Thymoquinone ameliorates the immunological and histological changes induced by exposure to imidacloprid insecticide
}

\author{
Mohamed Mohany ${ }^{1,3}$, Mostafa El-Feki $^{3}$, Inas Refaat ${ }^{3}$, Olivier Garraud ${ }^{2,5}$ and Gamal Badr ${ }^{1,4}$ \\ ${ }^{1}$ Zoology Department, College of Science, King Saud University, 11451 Riyadh, Saudi Arabia \\ 2 Vice-Rectorate for Graduate Studies and Research-Visiting Professor Program, King Saud University \\ ${ }^{3}$ Zoology Department, Faculty of Science, Minia University, Egypt \\ ${ }_{4}^{4}$ Zoology Department, Faculty of Science, Assiut University, 71516 Assiut, Egypt \\ ${ }^{5}$ Etablissement Français du Sang Auvergne-Loire \& EA3064 - GIMAP, Université de Lyon, \\ F-42023, Saint-Etienne (cedex 2), France
}

(Received September 29, 2011; Accepted October 26, 2011)

\begin{abstract}
Previous studies have shown that thymoquinone (TQ) exerts protective effects in some models of pesticide-induced immunotoxicity. However, no data exist regarding its possible modulatory effect during imidacloprid (IC)-induced toxicity. Therefore, the aim of this study was to investigate the impact of TQ on IC-induced immunotoxicity. Sixty adult male albino rats were divided into three groups of twenty animals each. The control group was given distilled water orally, while the IC-treated group was orally administered $0.01 \mathrm{LD}_{50}(0.21 \mathrm{mg} / \mathrm{kg}$ body weight $)$ of IC insecticide daily for 28 days. The animals in the third group (IC/TQ group) received the same IC dose as the IC-treated group for 28 days in addition to an intraperitoneal (I.P.) injection of TQ ( $1 \mathrm{mg} / \mathrm{kg}$ ) once every 7 days. We found that IC induced significant increases $(\mathrm{P}<0.05)$ in total leukocyte counts, total immunoglobulins (Igs) (especially IgGs), the hemagglutination of antibodies, alanine aminotransferase (ALT), aspartate aminotransferase (AST), alkaline phosphatase (ALP) and malondialdehyde (MDA) compared to the control group. In contrast, significant decreases $(\mathrm{P}<0.05)$ in phagocytic activity, chemokine expression and chemotaxis were observed in the IC-treated group, as were severe histopathological lesions in the liver, spleen and thymus. Notably, TQ supplementation ameliorated the biochemical, histopathological, and immunological changes induced by IC by increasing phagocytic activity, chemokinesis, chemotaxis, immunoglobulin levels, and the hemagglutination of antibodies, as well as by decreasing hepatic enzymes and serum MDA levels. Taken together, our data reveal the benefits of TQ supplementation for ameliorating IC toxicity by decreasing oxidative stress and enhancing immune efficiency.
\end{abstract}

Key words: Hepatotoxicity, Imidacloprid, Immunotoxicity, MDA, Phagocytic activity, Thymoquinone

\section{INTRODUCTION}

The uncontrolled use of pesticides in agriculture presents a high risk for public health. Pollutant pesticides reach the human body in everyday meals and can be deposited and accumulate in various tissues. Imidacloprid (IC), or 1-(6-chloro-3-pyridylmethyl)-N-nitro-imidazolidin-2-ylideneamine, is a member of the neonicotinoid insecticide class and is highly effective against a variety of insects. IC acts on the nervous system by blocking postsynaptic acetylcholine receptors, which kills the insect (Tomizawa and Casida, 2005). Due to its acute toxicity in insects but low vertebrate toxicity, IC has become one of the most widely used insecticides in the world (Ware and Whitacre, 2004).

Immunotoxicology is the discipline concerned with the interactions between toxins substances and the immune system (Banerjee et al., 2001). Despite the large body of literature addressing immune responses during insecticide exposure, the immunotoxicity of IC is poorly understood. Because it is important for assessing the safety of drugs and non-drug chemicals, immunotoxicity testing is

Correspondence: Gamal Badr (E-mail: badr73@yahoo.com) 
required by many regulatory agencies (Holsapple, 2003). Additionally, the histological technique has been widely used as a potential toxicity marker for different environmental pollutants, including insecticides (Bhuiyan et al., 2001). There have been few studies regarding ICmediated immune system effects using hemagglutination antibody titers (HAT), the delayed-type hypersensitivity (DTH) response, leukocyte migration inhibition (LMI) against sheep red blood cells (RBCs) and the phagocytic index. Progressive and proportional decreases in HAT and DTH responses were observed in IC-treated rats. The phagocytic index and leukocyte migration were also found to be reduced, suggesting immunotoxic effects (Gatne et al., 2006). Previous IC studies have shown genotoxicity in both rats (Karabay and Oguz, 2005) and cultured human lymphocytes (Demsia et al., 2007). Moreover, neurobehavioral deficits were found in rats exposed to IC in utero (Abou-Donia et al., 2008).

Several classes of antioxidant dietary compounds have been suggested to have health benefits. The evidence shows that the consumption of these products leads to decreases in various pro-inflammatory and/or oxidative stress biomarkers (Vouldoukis et al., 2004). Thymoquinone (TQ) is an abundant component of black seed (Nigella sativa) oil extract. Its beneficial effects are related to its anti-oxidant, anti-infective, anti-tumor and antiinflammatory properties (Ragheb et al., 2009). Previous laboratory studies have revealed that oral administration of TQ protected several organs against the oxidative damage induced by a variety of free radical-generating agents, including doxorubicin-induced cardiomyopathy (Nagi and Mansour, 2000), carbon tetrachloride-evoked hepatotoxicity (Mansour, 2000) and the renal damage caused by ifosfamide (Badary, 1999). Furthermore, a protective effect of TQ against infection-induced genotoxicity has been reported (Aboul-Ela, 2002). Recently, Alenzi et al. (2010) suggested that TQ could lower cyclophosphamide-induced toxicity, as shown by an up-regulation of antioxidant mechanisms, indicating a potential clinical application for this agent to minimize the toxic effects of anticancer drug treatment. One of the valuable properties of black seed is the immunomodulatory effect of its constituents. Salem (2005) summarized the immunomodulatory and therapeutic properties of black seeds and emphasized the potent immunomodulatory effects of this plant. Additionally, the potential of $N$. sativa oil to enhance cellular immunity and the functions of innate immune cells, including macrophages and natural killer (NK) cells, has been well documented (Fararh et al., 2004). Although numerous studies have reported that TQ protected several organs against oxidative damage, few data are avail- able concerning its effects on IC-induced immunotoxicity. Therefore, in this study, we investigated the possible mechanism of TQ-mediated amelioration of the immunological and histological changes induced by exposure to IC insecticide.

\section{MATERIALS AND METHODS}

\section{Experimental animals}

Sixty adult male, 6- week old age albino rats (Rattus norvegicus) weighing 150-170 g were obtained from the General Organization of Serum and Vaccine (GOSV), Helwan farm, Egypt. All animal procedures were performed in accordance with the guidelines for the care and use of experimental animals of the Committee for the Purpose of Supervision of Experiments on Animals (CPCSEA) and the National Institutes of Health (NIH). The study protocol was approved by the Animal Ethics Committee of the Zoology Department at the College of Science, Minia University according to Helsinki principles. The animals were allowed to acclimatize in metal cages inside a well-ventilated room for 2 weeks prior to the experiment. They were maintained under standard laboratory conditions $\left(23^{\circ} \mathrm{C}\right.$, relative humidity $60-70 \%$ and a $12 \mathrm{hr}$ light/dark cycle) and were fed a diet of standard commercial pellets and water.

\section{Preparation of thymoquinone}

TQ was purchased from Sigma Chemical Company (St Louis, MO, USA). The compound was > 99\% pure and reconstituted in distilled water at a concentration of $4 \mathrm{mg} / \mathrm{ml}$. This stock was stored at $4^{\circ} \mathrm{C}$ in $15-\mathrm{ml}$ centrifuge tubes wrapped in aluminum foil to prevent dimer formation.

\section{Insecticide administration}

IC is produced by the Bayer Company under the trade name Confidor. The commercial formulation (Confidor $20 \%$ EC) was obtained from the Bayer Scientific Office in Cairo, Egypt. IC was administered orally using a bluntended syringe needle. For the preparation, $1 \mathrm{ml}$ of Confidor $20 \%$ EC was dissolved in $99 \mathrm{ml}$ of distilled water and administered at a dose of $1 / 100 \mathrm{LD}_{50}, 0.21 \mathrm{mg} / \mathrm{kg}$ in a solution that was freshly prepared within 5 min of administration.

\section{Experimental design}

Twenty adult male albino rats (Rattus norvegicus), of 6- week old age and weighing 150-170 g, were used in preliminary study for $\mathrm{LD}_{50}$ determination. In this study different concentrations of IC were dissolved in distilled water and orally administered to rats as a single dose. The 
Thymoquinone decreases immunotoxicity induced by imidacloprid insecticide

control rats received distilled water only. After $24 \mathrm{hr}$, the $\mathrm{LD}_{50}$ toxicity value was calculated. The effects of IC and TQ on immune response, oxidative stress, and the liver enzymes of the rats were studied by dividing the animals into three groups of 20 animals each. The control group was orally administered distilled water daily for 28 days. The IC-treated group was administered daily oral treatments of $0.01 \mathrm{LD}_{50}(0.21 \mathrm{mg} / \mathrm{kg}$. bwt $)$ of IC insecticide for 28 days. The animals in group 3 (TQ supplemented IC group) received the same IC dose as the IC-treated group for 28 days but were also given TQ once every 7 days (1 mg/kg. bwt, I.P.).

\section{Collection of blood and tissue samples}

At the end experimental period (28 days), twenty rats from each group were killed by anesthesia with pentobarbital (60 mg/kg body weight), and blood samples were collected from the orbital venous plexus into plain tubes, and two blood samples were immediately collected. The first sample was collected in a heparinized tube (2.25 $\mu \mathrm{l}$ heparin $/ 5 \mathrm{ml}$ blood) for chemotaxis, chemokinesis, phagocytosis and white blood cell count assays. The second sample was collected in a non-heparinized tube and centrifuged for $10 \mathrm{~min}$ at 3,000 rpm to separate the serum, which was then stored at $-80^{\circ} \mathrm{C}$ to measure the immunoglobulin content and other biochemical parameters. During the animal dissections, the liver, spleen, and thymus were removed, wiped with filter paper and fixed in $10 \%$ neutral buffered formalin fixative for histopathological examination.

\section{Total leukocyte count and phagocytosis}

White blood cells were counted as previously described (Schalm et al., 1975). The phagocytic activity of macrophages and other phagocytic cells in whole blood was examined using phase contrast microscopy. The whole blood was stored in cold $0.9 \%$ saline solution, and one drop of each sample was examined with phase contrast microscopy in a drop of paraffin oil. The phagocytosis ratios were then calculated, and notable phagocytic states were photographed (Abu El-Maged, 1991).

\section{Chemokinesis assay}

A modified Boyden's chamber assay was used to more precisely quantify the chemotactic response (Boyden, 1962). In this assay, cells migrate through a micropore filter from a starting compartment into an adjacent one containing a chemoattractant. For the method employed here (Gearing and Rimmer, 1985), the two compartments were formed by the wells of two stacked microtitration plates, with cellulose acetate micropore filters ( $5 \mu \mathrm{m}$ Millipore
67/20, Molsheim, France) partitioning the wells. Fivemicrometer micropore filters were then placed over all the lower wells. The upper plate was inverted and placed over the lower plate with petroleum jelly around the perimeter joining the plates. Blood $(0.3 \mathrm{ml})$ was introduced into each chamber through a hole made in the base of each well. The entire plate was then covered with aluminum foil to reduce evaporation and placed in humid incubator at $37^{\circ} \mathrm{C}$ for $16-18 \mathrm{hr}$. Following incubation, the fluid was removed from the upper wells with a syringe and replaced with $0.3 \mathrm{ml}$ of methanol to fix the cells. After $20 \mathrm{~min}$, the methanol was removed, and the two plates were separated. The filter papers were then fixed in $10 \%$ formalin for $20 \mathrm{~min}$, stained in Delafield's hematoxylin for $5 \mathrm{~min}$, washed with distilled water and mounted in Canada balsam on a glass microscope slide with the bottom surface facing upward. Two counts were made on each of 5 filters. The chemokinetic effect obtained was expressed using a chemokinetic index which is defined as mean number of cells with chemokinetic stimulus over mean number of cells with control stimulus.

\section{Agarose gel chemotaxis movement assay}

A chemotaxis assay was used to study the chemotactic response of leukocytes in response to imidacloprid. A previously described method was employed (Nelson et al., 1975; Comer et al., 2005), in which cells migrate from a well cut into an agarose gel into a well containing a chemotactic stimulus. The assay was performed in sterile Petri dishes. The agarose gels were prepared in 100-ml volumes by first dissolving $0.8 \mathrm{~g}$ of agarose (BDH) in $38 \mathrm{ml}$ of $0.9 \%$ saline solution in a boiling water bath for $20 \mathrm{~min}$. Next, $1 \mathrm{ml}$ of $1 \%$ fetal calf serum (FCS) and $1 \mathrm{ml}$ of combined penicillin and streptomycin (flow) were added to the gel as it cooled. The FCS was sterilized by filtering it through a disposable 0.22-mm Millex filter unit. The mixture was added to the Petri dishes in 10-ml aliquots using a pre-warmed sterile pipette. The gel was then allowed to set on a level table at room temperature and was stored at $4{ }^{\circ} \mathrm{C}$ until use. For each assay, two groups of three 2.5$\mathrm{mm}$ diameter wells separated by $2.5 \mathrm{~mm}$ were made in the gel. Three Petri dishes were used for each test, corresponding to six replicates for each. The central wells received $10 \mu \mathrm{l}$ of blood. The wells on one side were used as controls and received $0.9 \%$ saline solution. The plates were covered and incubated for $16-18 \mathrm{hr}$ at $38-42^{\circ} \mathrm{C}$ and $95 \%$ humidity. The migrated cells were fixed in methanol for $30 \mathrm{~min}$. The plates were coded and read independently by two separate blinded observers. The observed chemotactic effect was expressed using a chemotactic index calculated similarly to the chemokinetic index. 


\section{Turbidity test for estimation of total immunoglobulin level (total Ig)}

For the current study, the $\mathrm{ZnSO}_{4}$ technique was performed as previously described (McEwan et al., 1970; Pfeiffer et al., 1977) for measuring immunoglobulin levels.

\section{Immunization and titration}

The detection of agglutinating antibodies was assessed using a passive hemagglutination technique described by Hudson and Hay (1980). A positive response is indicated by the formation of a mat of agglutinated RBCs on the bottom of the well. If no agglutination occurs, the individual cells form a pellet on the base of the V-shaped well. The negative $\log _{2}$ of the maximum dilution at which agglutination occurred was recorded for each serum sample tested.

\section{Determination of serum IgG and IgM}

Serum IgG and IgM levels were determined by an immunoprecipitation in agarose between an antigen and its homologous antibody, which was performed as previously described (Berne, 1974). This procedure is performed by incorporating an immune reactant (usually an antibody) uniformly throughout a layer of agarose gel and then introducing the other reactants (usually antigens) into wells carved in the gel. The antigen diffuses radially out of the well into the surrounding gel-antibody mixture, and a visible ring of precipitate forms where the antigen and antibody react. There is a quantitative relationship between the ring diameter and the antigen concentration. While the precipitate is expanding, the ratio between the ring diameter and the antigen concentration logarithm is approximately linear. This relationship is useful when rapid estimations are required.

\section{Liver enzyme assays and lipid peroxide (malondialdehyde)}

Aspartate and alanine transaminase levels were assayed using a colorimetric method (Reitman and Frankel, 1957) with a Roche Diagnostic Reflotron. Serum alkaline phosphatase activity was determined as previously described (Belfield and Goldberg, 1971) using a specific kits purchased from a biodiagnostic chemical company (Cairo, Egypt). Lipid peroxides are unstable indicators of oxidative stress in cells that decompose to form more complex and reactive compounds such as malondialdehyde (MDA). Thiobarbituric acid-reactive substances (TBARS), the final products of lipid peroxidation, were assayed spectrophotometrically, as previously described (Satoh, 1978).

\section{Histopathology}

The liver, spleen and thymus were preserved in $10 \%$ formalin immediately following their removal from the animal.

\section{Tissue processing}

The liver, spleen and thymus tissues were placed in $10 \%$ formalin (diluted to $10 \%$ with normal saline) for $1 \mathrm{hr}$ to reverse the shrinkage that had been caused by the high concentration of formalin. The tissues were dehydrated in an ascending grade of isopropyl alcohol by immersion in $80 \%$ isopropanol overnight and in $100 \%$ isopropyl alcohol for $1 \mathrm{hr}$. The dehydrated tissues were cleared in two changes of xylene for $1 \mathrm{hr}$ each. The wax-impregnated tissues were embedded in paraffin blocks using wax of the same grade. The paraffin blocks were mounted and cut with a rotary microtome at a 3-micron thickness. The sections were floated in a tissue floatation bath at $40^{\circ} \mathrm{C}$ and placed on glass slides that were smeared with equal parts of egg albumin and glycerol. The sections were then melted in an incubator at $60^{\circ} \mathrm{C}$ for $5 \mathrm{~min}$ and allowed to cool.

\section{Tissue staining}

The sections were deparaffinized by immersion in xylene for $10 \mathrm{~min}$ in a horizontal staining jar. The deparaffinized sections were washed in $100 \%$ isopropyl alcohol and stained in Ehrlich's hematoxylin for 8 min in a horizontal staining jar. After staining in the hematoxylin, the sections were washed in tap water and dipped in acid alcohol to remove the excess stain $(8.3 \% \mathrm{HCl}$ in $70 \%$ alcohol). The sections were then placed in running tap water for $10 \mathrm{~min}$ to promote bluing (slow alkalization). The sections were counter-stained in $1 \%$ aqueous eosin ( $1 \mathrm{~g}$ in $100 \mathrm{ml}$ tap water) for $1 \mathrm{~min}$, and the excess stain was washed in tap water before the sections were dried. The complete dehydration of the stained sections was achieved by placing the sections in an incubator at $60^{\circ} \mathrm{C}$ for $5 \mathrm{~min}$. When the sections were cooled, they were mounted in DPX mount, which has the optical index of glass (the sections were wetted in xylene and inverted onto the mount and then placed on the cover slip). The architecture was observed using a low-power objective under a microscope.

\section{Statistical analysis}

All data are expressed as means \pm S.E. The statistical analysis was performed using one-way ANOVAs followed by post-hoc tests for multiple comparisons using SPSS 10.0 for Windows. P-values less than 0.05 were considered statistically significant. 
Thymoquinone decreases immunotoxicity induced by imidacloprid insecticide

\section{RESULTS}

\section{IC-mediated toxicity effect}

We first investigated the $\mathrm{LD}_{50}$ of IC using oral administration of different concentrations of IC. The $\mathrm{LD}_{50}$ value was $451 \mathrm{mg} / \mathrm{kg}$ for the male Wistar rats used in this study (Fig. 1).

\section{TQ supplementation enhances innate immunity during IC toxicity}

We monitored changes in immunological parameters related to innate immunity in all animal groups throughout the experiment period. We observed a significant increase in total leukocyte counts compared with the control group $\left({ }^{*} \mathrm{P}<0.05\right)$ after oral administration of 0.01 $\mathrm{LD}_{50}$ IC. A significant decrease in the total leukocyte count was measured in the TQ-supplemented IC group compared with the IC-treated group (\#P<0.05) (Fig. 2A). The immune response kinetics of the treated animals were determined by measuring phagocytosis, chemokinesis, and leukocyte chemotaxis in whole blood. IC administration induced significant decreases in leukocyte phagocytic activity, chemokinesis, and chemotaxis compared with the control group $(* \mathrm{P}<0.05)$ (Figs. $2 \mathrm{~B}, \mathrm{C}$ and $\mathrm{D}$ ). We observed significant increases in phagocytic activity, chemokinesis and chemotaxis in the TQ-supplemented IC group compared with the IC-treated $(\# \mathrm{P}<0.05)$ and control groups $(+\mathrm{P}<0.05)$. Because the TQ-treated rats displayed elevations in phagocytic activity and chemokinesis, notable phagocytic states and migrating leucocytes were photographed (Figs. 3A, B).

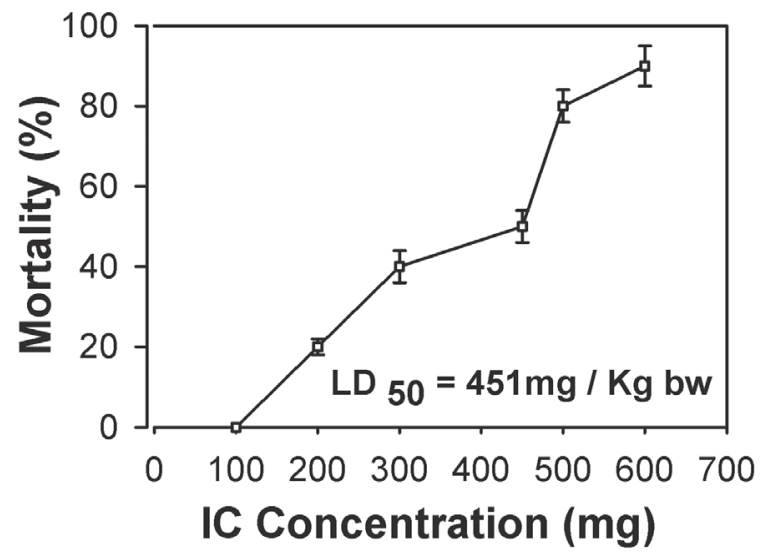

Fig. 1. Determination of the $\mathrm{IC}_{\mathrm{LD}}$ in male rats as $451 \mathrm{mg} / \mathrm{kg}$. The results are expressed as means \pm S.E.M.
A

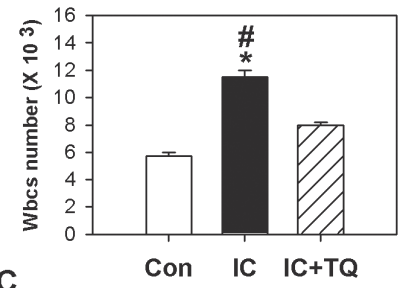

C
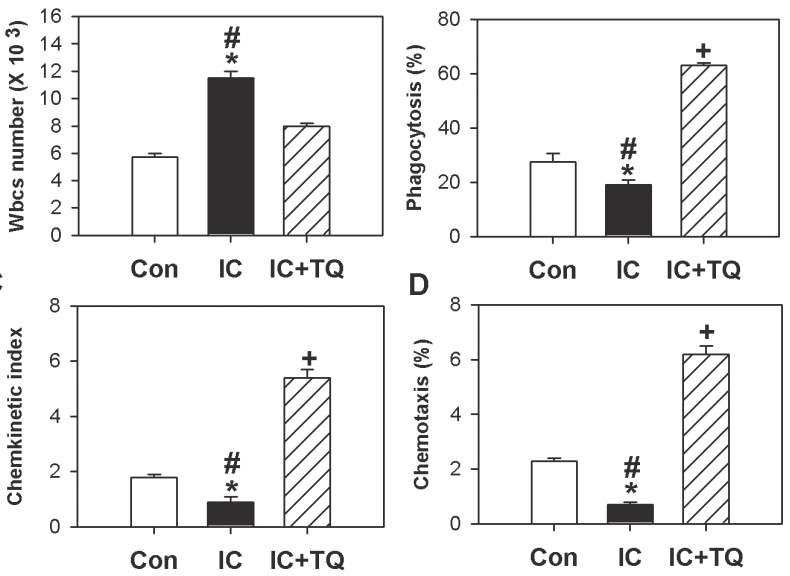

Fig. 2. Effects of TQ supplementation on white blood cell counts, phagocytic activity, the chemokinetic index, and chemotaxis during IC-induced toxicity. Innate immunological parameters were measured in three groups of rats. The results are presented as means \pm S.E.M $(\mathrm{n}=20)$, as described in the methods section. ${ }^{*} \mathrm{P}<0.05$, IC vs. control; \# $\mathrm{P}<0.05$, IC vs. TQ; ${ }^{+} \mathrm{P}<$ 0.05 , TQ vs. control (ANOVA followed by a post-hoc test for multiple comparisons).

\section{TQ treatment increases serum immunoglobulin levels}

We next investigated changes in serum immunoglobulins after short-term oral IC administration and TQ supplementation. IC treatment induced a significant increase in total Igs, IgG levels, and hemagglutination of antibodies compared with the control group $(* \mathrm{P}<0.05)$ (Figs. 4A, B and C). However, the administration of IC did not affect the IgM levels (Fig. 4D). Obvious increases were observed in the total levels of $\operatorname{Ig}, \operatorname{IgG}, \operatorname{IgM}$, and antibody hemagglutination in the TQ-supplemented IC group compared with the IC-treated ( $\left.{ }^{*} \mathrm{P}<0.05\right)$ and control groups $\left({ }^{+} \mathrm{P}<0.05\right)$ (Figs. 4A, B, C and D).

\section{TQ supplementation decreases elevated liver enzymes and MDA during IC hepatotoxicity}

We monitored hepatic dysfunction caused by IC toxicity by measuring the AST, ALT, and ALP liver enzymes. As shown in Figs. 5 (A, B and C), AST, ALT and ALP levels were significantly increased after oral IC administration compared with the control rats $\left({ }^{*} \mathrm{P}<0.05\right)$. In the TQ-supplemented IC group, a significant decrease in the elevated liver enzymes (AST, ALT, ALP) was observed compared with the IC-treated group ( $\left.{ }^{*} \mathrm{P}<0.05\right)$. MDA is a marker of oxidative lipid damage and a major oxida- 

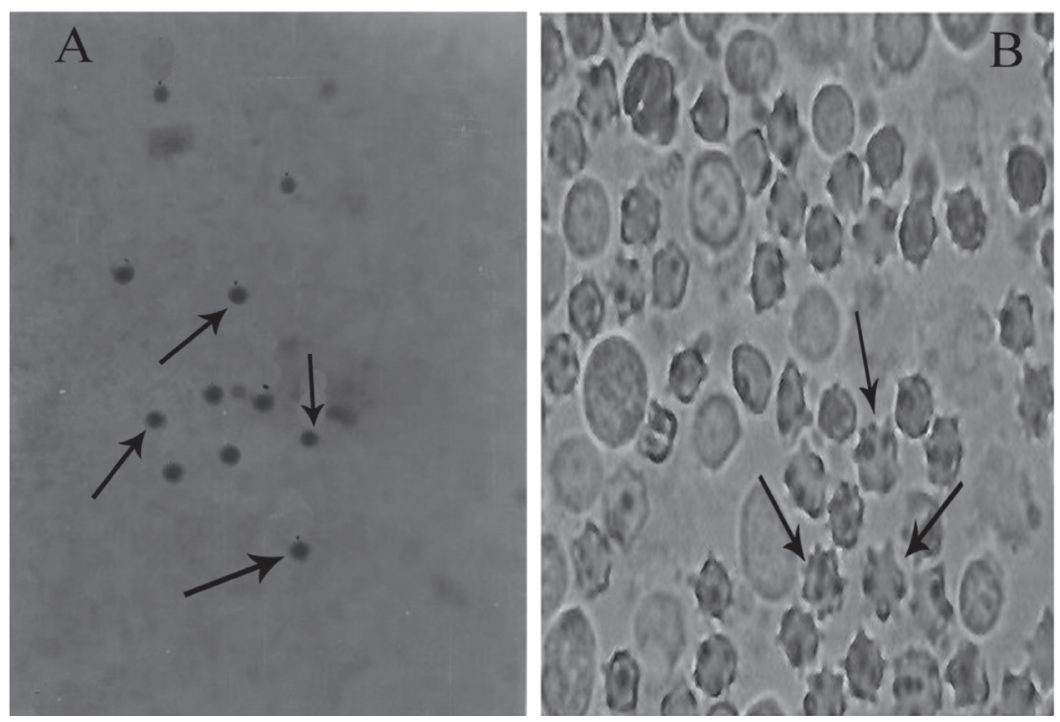

Fig. 3. Effects of TQ supplementation on migrating leucocytes and phagocytic activity during IC-mediated toxicity. TQ supplementation resulted in increased numbers of migrating leucocytes through micropore filters toward an IC stimulus (arrows; H\&E, $\times 500)(A)$. The phagocytic activity of TQ-treated rats (B). Note that most of the cells were lysed (arrows; phase contrast microscopy, $\times 500)$.

A
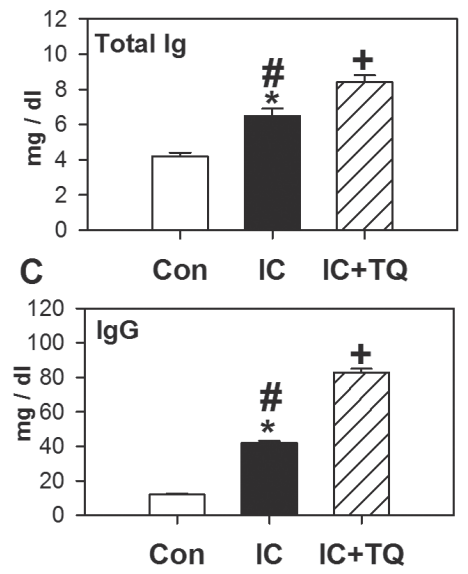

B
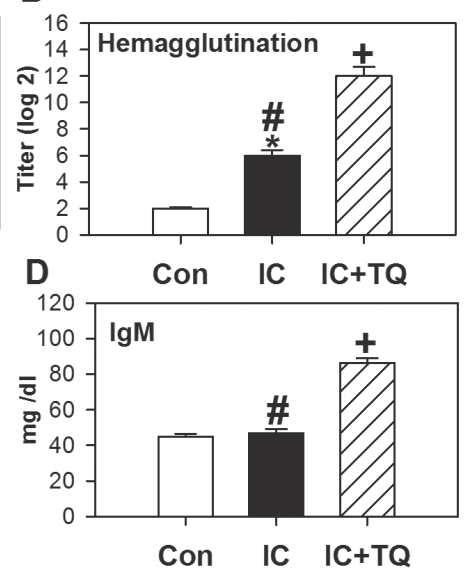

Fig. 4. IC-mediated changes in immunoglobulin levels and hemagglutination are modulated by TQ supplementation. Data showing the total Ig levels, the hemagglutination assay results, IgGs, and IgMs in each group are expressed as means \pm S.E.M. in the control (open bars), IC-treated (black bars) and TQ-supplemented (hatched bars) rats. ${ }^{*} \mathrm{P}<0.05$, IC vs. control; ${ }^{\#} \mathrm{P}<0.05$, IC vs. TQ; ${ }^{+} \mathrm{P}<0.05$, TQ vs. control.

tive product of peroxidized polyunsaturated fatty acids (Zhang et al., 2004). MDA levels significantly increased in the IC-treated group compared with the control group $\left({ }^{*} \mathrm{P}<0.05\right)$ (Fig. 5D). Moreover, TQ induced a significant decrease in MDA levels in the TQ-supplemented IC group compared to the IC-treated group ( $\left.{ }^{\mathrm{P}}<0.05\right)$.

\section{TQ treatment reverses the histological changes in the spleen and thymus induced by IC immunotoxicity}

We next investigated whether TQ supplementation could reverse the histological changes in the spleen and thymus mediated by IC toxicity. The normal spleens in 
Thymoquinone decreases immunotoxicity induced by imidacloprid insecticide
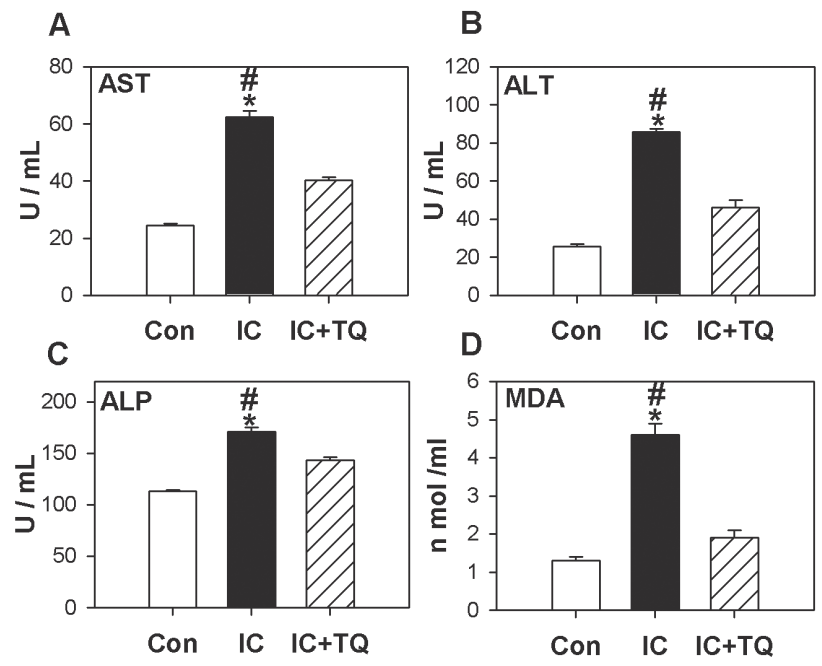

Fig. 5. IC-mediated elevated serum hepatic enzymes and MDA levels are diminished by TQ supplementation. Blood biochemical parameters were measured in the three groups of rats, and the results are presented as means \pm S.E.M. $(n=20)$, as described in the methods section. ${ }^{*} \mathrm{P}<0.05$, IC vs. control; \# $\mathrm{P}<0.05$, IC vs. TQ; ${ }^{+} \mathrm{P}<0.05$, TQ vs. control.

the control group displayed a splenic parenchyma composed of white and red pulp surrounded by a capsule of dense connective tissue from which trabeculae emanated, dividing the splenic parenchyma into incomplete compartments (Fig. 6A). In comparison, the white pulp spleen sections of animals treated with $0.01 \mathrm{LD}_{50}$ of IC for 28 days were larger and had low lymphocyte densities, more fibroblasts, red pulp congested with red blood cells, more bundles (such as trabeculae), and some pyknotic lymphocytes (Fig. 6B). Most of the histological changes due to IC toxicity were reversed by TQ supplementation, including an improvement in the lymphocytic population and leukocyte infiltration. Phagocytosis was visible as dark yellow-brown pigments and macrophages in the TQ-supplemented IC group (Fig. 6C). When compared with the control rats, the thymi of animals treated with $0.01 \mathrm{LD}_{50}$ of IC for 28 days exhibited lymphocytic depletion, lymphocyte invasion, fibroblasts, occasional eosinophilic cells, pyknotic nuclei and focal areas of macrophage activity (Figs. 6D and E). Histological alterations of the thymus due to IC toxicity were modulated by TQ supplementation, which was associated with increases in the lymphocytic population and the number of rosettes (Fig. 6F).

\section{TQ treatment reverses IC-mediated liver histological alterations}

Because the liver is the principal target of IC toxicity, we monitored liver histological changes between the treatment groups. When compared with the control rats (Fig. 7A), liver sections from animals treated with 0.01 $\mathrm{LD}_{50}$ of IC for 4 weeks showed a heavily congested central vein and blood sinusoids, widely distributed pyknotic nuclei, and leukocyte infiltration (Fig. 7B). Most of these histological changes were modulated by TQ supplementation. TQ-treated livers had a normal, decongested central vein, few pyknotic nuclei and no congestion of liver sinusoids with blood cells (Fig. 7C).

\section{DISCUSSION}

Pesticides have modulatory effects on the immunological system. Most often these effects are immunosuppressive, but they can sometimes be stimulatory, depending on the type of compound and the dose and type of antigen stimulus. The immunosuppressive effects of pesticides may also be associated with an increased cancer risk, as an increase in the number of cases has recently been observed among agricultural workers (Sathiakumar et al., 2011). We investigated the possible modulatory effect of TQ on the immunotoxicity and histological changes induced by exposure to IC insecticide. First, we observed a significant increase in total leukocyte counts in the IC treated group. Similar observations have been made by Ammar et al. (2003) who reported that 0.1 and 0.25 LD50 of IC insecticide induced significant increase in total leucocyte count in male albino rats that may be related to the increase in lymphocytes counts. The data indicate that IC administration induced a significant decrease in leukocyte phagocytic activity, chemokinesis, and chemotaxis. This reduction may be due to suppression of the antibody response (El-Gohary et al., 2005). Moreover, IC-induced changes in the hematopoietic organs and increased migration inhibition factor (MIF) activity, which suppresses the mobility of macrophages and neutrophils, reducing their ability to reach inflammatory sites. Interestingly, TQ treatment caused significant increases in phagocytic activity, chemokinesis and chemotaxis.

TQ may activate macrophage phagocytic activity by acting as an ROS scavenger and by normalizing the elevated levels of macrophage-derived inflammatory mediators (El-Mahmoudy et al., 2005). The levels of serum total Ig, IgGs, and the hemagglutination of antibodies were also significantly increased by IC administration. These increases may be due to lymphocyte activation 


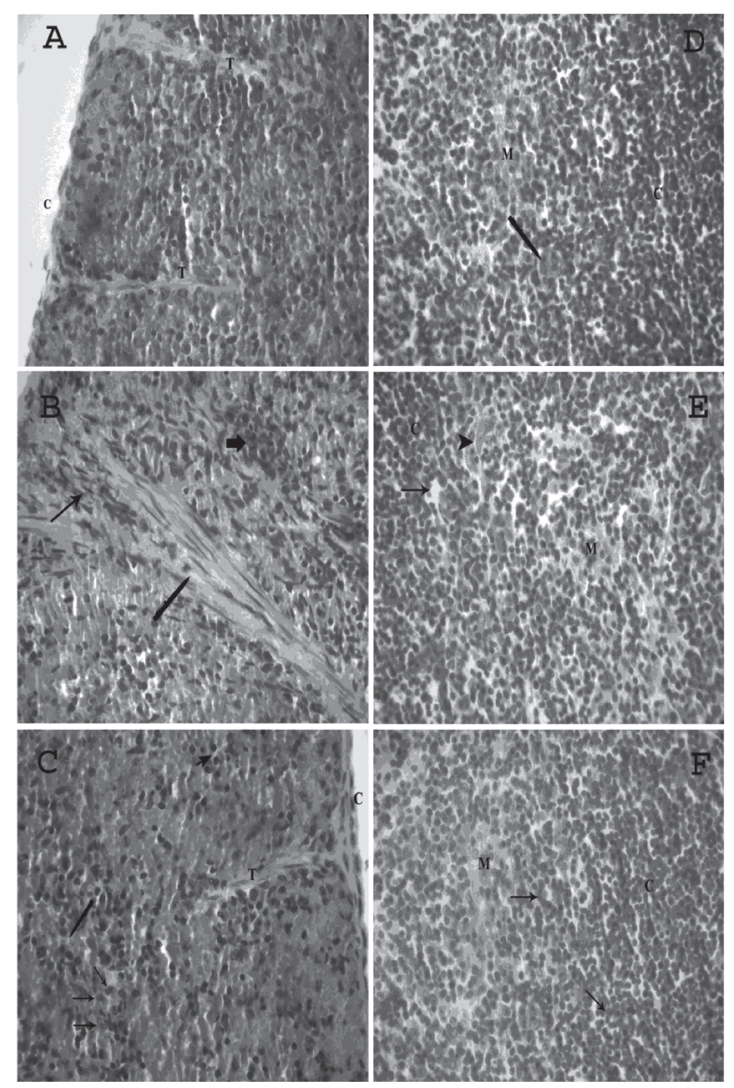

Fig. 6. Oral administration of IC induces marked changes in the histological architecture of the spleen and thymus that are reversed by TQ treatment. The results show the effects of IC and TQ on histopathological changes in the spleen and thymus after rats were randomly divided into three different groups of 20 animals each: control, IC, and IC+TQ. Spleen and thymus specimens from each group were removed for histopathological examination, fixed in $10 \%$ neutral buffered formalin, sectioned at $3 \mu \mathrm{m}$ and stained with hematoxylin and eosin (H\&E) for light microscopic examination. Sections of control rat spleens showing outer capsules $(C)$ and extending trabeculae $(T)$ are shown $(H \& E, \times 500)(A)$. Spleen sections from rats treated with $0.01 \mathrm{LD}_{50}$ of IC for 28 days show fibroblasts (thin arrows), large bundles of fibers (pen arrows), and small nests of pyknotic nuclei (thick arrows) $(\mathrm{H} \& \mathrm{E}, \times 500)(\mathrm{B})$. Spleens from rats treated with IC+TQ show improvements in the lymphocytic population, with capsules (C) and trabeculae (T), as well as infiltration of leucocytes (arrowhead). Phagocytosis is visible as dark yellow-brown pigments (pen arrow) and macrophages (thin arrow) $(\mathrm{H} \& \mathrm{E}, \times 500)(\mathrm{C})$. A section of the thymus from a control rat shows the cortex (C) and medulla (M). Note Hassall's corpuscle (pen arrow) $(H \& E, \times 500)(D)$. A section of the thymus from a rat treated with $0.01 \mathrm{LD}_{50}$ of IC after 28 days shows the cortex $(\mathrm{C})$ and medulla $(\mathrm{M})$ with lymphocytic depletion, invasion of fibroblasts (arrowhead) and focal areas of macrophage activity (thin arrow) (H\&E, $\times 500)$ (E). The thymus from a rat treated with IC + TQ shows the cortex (C) and medulla (M) with increased lymphocytic population and multiple rosettes (arrows) $(\mathrm{H} \& \mathrm{E}, \times 500)(\mathrm{F})$.

(Neishabouri et al., 2004). The increase in total Ig levels induced by TQ supplementation may be mediated by the improvement of immunofunctional abnormalities and increasing antibody levels (El Gazzar et al., 2006). Our data show that serum AST, ALT, ALP, and MDA levels were significantly increased by IC administration. Our results are supported by those of Balani et al. (2011), who studied male White Leghorn (WLH) chicks treated with different concentrations of IC. The increases in the lev- els of specific enzymes correlate well with the gross and histopathological changes we observed in livers. Kapoor et al. (2010) investigated the effects of IC on antioxidant enzymes and lipid peroxidation and made similar observations. In our study, we found that TQ decreased the elevated hepatic enzymes and MDA levels that were induced by IC administration. Fascinatingly, TQ supplementation also prevented the IC-induced increase in hepatic enzymes, suggesting that TQ may have protective effect 
Thymoquinone decreases immunotoxicity induced by imidacloprid insecticide
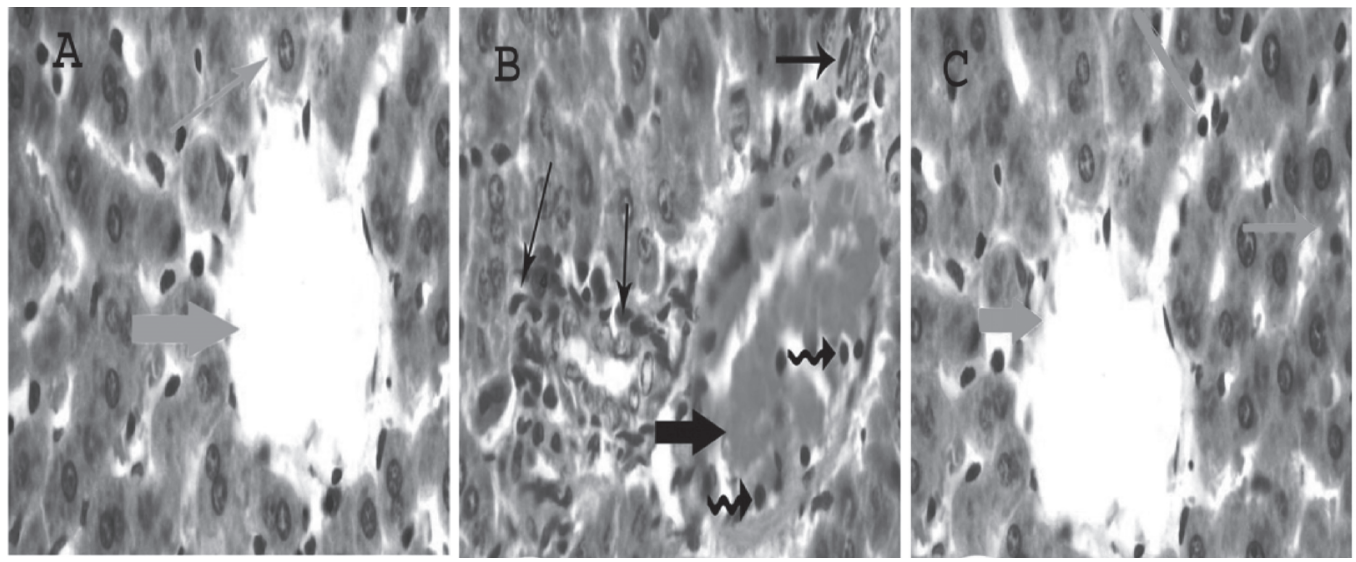

Fig. 7. Oral administration of IC induces distinct alterations in liver histology that are reversed by TQ supplementation. The liver from a control rat shows normal hepatocytes (thin arrow) and central vein (thick arrow) (H\&E, $\times 500)(A)$. A liver section from a rat that received $0.01 \mathrm{LD}_{50}$ of IC for 28 days shows hepatocytes with a homogenous cytoplasm, a central vein congested with red blood cells (thick arrow), infiltration of leukocytes (zigzag arrow) and fibroblasts around the bile duct and central vein (thin arrow) $(\mathrm{H} \& \mathrm{E}, \times 500)(\mathrm{B})$. The liver from a rat treated with IC+TQ shows a normal decongested central vein (thick arrow) with small pyknotic nuclei (pen arrow) and congested liver sinusoids with blood cells (thin arrow) $(\mathrm{H} \& \mathrm{E}, \times 500)(\mathrm{C})$.

against IC-induced liver damage. Similar observations have been made by Lebda et al. (2011), who revealed that pretreatment with TQ inhibited the liver enzyme leakage and lipid peroxidation induced by D-galactosamine. These findings indicate that the membrane-stabilizing effect of TQ may stem from its ability to scavenge the free radicals produced by D-galactosamine and to protect liver cells against oxidative damage. The toxic effects of IC were further shown by histopathological changes in the spleen, thymus and liver, which may be attributed to a loss of infiltration efficiency (Balani et al., 2008). Additionally, these results are in accordance with the histopathological lesions observed in livers of Japanese quail exposed to $139 \mathrm{mg} / \mathrm{kg}$ of IC (Kammon et al., 2010). Notably, most of the histological changes in the liver, spleen and thymus were reversed by TQ supplementation. Similar observations have been made by Sayed-Ahmed et al. (2010), who attributed these improvements to the ability of TQ to decrease oxidative stress and preserve the mRNA expression and activity of antioxidant enzymes.

In conclusion, the present data expand on our knowledge regarding the role of TQ supplementation for ameliorating the underlying mechanisms of IC-induced toxicity and suggest that TQ may be a promising drug candidate for immunomodulation.

\section{ACKNOWLEDGMENTS}

The authors extend their appreciation to the Deanship of Scientific Research at King Saud University for funding this work through research group no. RGP- VPP -078 .

\section{REFERENCES}

Abou-Donia, M.B., Goldstein, L.B., Bullman, S., Tu, T., Khan, W.A., Dechkovskaia, A.M. and Abdel-Rahman, A.A. (2008): Imidacloprid induces neurobehavioral deficits and increases expression of glial fibrillary acidic protein in the motor cortex and hippocampus in offspring rats following in utero exposure. J. Toxicol. Environ. Health A, 71,119-130.

Aboul-Ela, E.I. (2002): Cytogenetic studies on Nigella sativa seeds extract and thymoquinone on mouse cells infected with schistosomiasis using karyotyping. Mutat. Res., 516, 11-17.

Abu El-Maged, A.A. (1991): Encapsulation, chemotactic and Chemokinetic activities of the haemocytes of different stages of periplaneta Americana. Bull. Fac. Sci. Assuit Univ. Egypt, 20, 109122.

Alenzi, F.Q., El-Bolkiny, Yel-S. and Salem, M.L. (2010): Protective effects of Nigella sativa oil and thymoquinone against toxicity induced by the anticancer drug cyclophosphamide. Br. J. Biomed. Sci., 67, 20-28.

Ammar, M., Rabeih, K., Abou El-Khear, A. and Nema, M. (2003): Hematological studies of some pesticides on albino rats, Rattus norvigecus albinus. Alex. J. Pharmaceut. Sci. Egy., 17, 21-27.

Badary, O.A. (1999): Thymoquinone attenuates ifosfamide-induced Fanconi syndrome in rats and enhances its antitumor activity in mice. J. Ethnopharmacol., 67, 135-1342. 
Balani, T., Agrawal, S. and Thaker, A.M. (2011): Hematological and biochemical changes due to short-term oral administration of imidacloprid. Toxicol. Int., 18, 2-4.

Balani, T., Agrawal, S. and Thaker, A.M. (2008): Effects of imidacloprid a neonicotinoid insecticide on the immune system of white leghorn cockerels. J. Vet. Pharm. Toxicol., 7, 27-30.

Banerjee, B.D., Seth, V. and Ahmed, R.S. (2001): Pesticide-induced oxidative stress: Perspectives and Trends. Rev. Env. Health, 16, 1-40.

Belfield, A. and Goldberg, D. (1971): Alkaline phosphatase colourimertic method. Enzyme, 12, 561.

Berne, G.H. (1974): Radial immunodiffusion (RID) plates for the determination of immunoglobulins and other proteins in biological fluids. Clin. Chem., 200, 61-89.

Bhuiyan, A.S., Nesa, B., Nessa, Q. (2001): Effects of Sumithion on the Histological Changes of Spotted Murrel, Channa punctatus (Bloch). Pakist. J. Biol. Sci., 4, 1288-1290.

Boyden, S.V. (1962): The chemotactic effect of mixtures of antibody and antigen on polymphorphonuclear leucocyte. J. Exp. Med., 115, 453466

Comer, F.I., Lippincott C.K., Masbad, J.J. and Parent, C.A. (2005): The PI3K-mediated activation of CRAC independently regulates adenylyl cyclase activation and chemotaxis. Curr. Biol., 15, 134139.

Demsia, G., Vlastos, D., Goumenou, M. and Matthopoulos, D.P. (2007): Assessment of the genotoxicity of imidacloprid and metalaxyl in cultured human lymphocytes and rat bone-marrow. Mutat. Res., 634, 32-39.

El Gazzar, M., El Mezayen, R., Marecki, J.C., Nicolls, M.R., Canastar, A. and Dreskin, S.C. (2006): Anti-inflammatory effect of thymoquinone in a mouse model of allergic lung inflammation. Int. Immunopharmacol., 6, 1135-1142.

El-Gohary, M.S., Safinaz, G.M., Khalil, R.H., El-Banna, S., Soliman, M.K. (2005): Immunosuppressive effects of metrifonate on oreochromis niloticus. Egy. J. Aquat. Res., 31, 448458.

El-Mahmoudy, A., Shimizu, Y., Shiina, T., Matsuyama, H., Nikami, H. and Takewaki, T. (2005): Macrophage-derived cytokine and nitric oxide profiles in type I and type II diabetes mellitus: effect of thymoquinone. Acta Diabetol., 42, 23-30.

Fararh, K.M., Atoji, Y., Shimizu, Y., Shiina, T., Nikami, H. and Takewaki, T. (2004): Mechanisms of the hypoglycaemic and immunopotentiating effects of Nigella sativa L. oil in streptozotocin-induced diabetic hamsters. Res. Vet. Sci., 77,123-129.

Gatne, M.M., Ramesh, M.M., Bhoir, P.S. and Deore, M.D. (2006): Immunotoxicity studies of imidacloprid in rats. Toxicol. Int., 13, 89-92.

Gearing, A. and Rimmer, J.J. (1985): Amphian lymphokines: 1. leucocyte chemotactic factors produced by amphibian spleen cells following antigenic and mitogenic challenge in vitro. Develop. Comp. Immunol., 7, 281-290.

Holsapple, M.P. (2003): Developmental immunotoxicity testing (a review). Toxicol., 185, 193-203.

Hudson, L. and Hay, F.C. (1980): Practical immunology. (Hudson, L. and Hay, F.C. Eds.), Blackwell Scientific Publications.

Kammon, A.M., Brar, R.S., Banga, H.S. and Sodhi, S. (2010): Patho-biochemical studies on hepatotoxicity and nephrotoxicity on exposure to chlorpyrifos and imidacloprid in layer chickens. Veterinarski. Arhiv., 80, 663-672.

Kapoor, U., Srivastava, M.K., Bhardwaj, S. and Srivastava, L.P. (2010): Effect of imidacloprid on antioxidant enzymes and lipid peroxidation in female rats to derive its No Observed Effect
Level (NOEL). J. Toxicol. Sci., 35, 577-581.

Karabay, N.U. and Oguz, M.G. (2005): Cytogenetic and genotoxic effects of the insecticides, imidacloprid and methamidophos. Genet. Mol. Res., 4, 653-662.

Kennedy, M.L., Smith, J.K. and Jones, W.T. (2005): The pharmacokinetics of methylmercury in new-born rats. J. Toxicol. Sci., 30, 126-135.

Lebda, F.M., Ahmed, M.A., Abd El Samad, A.A. and Shawky, M.K. (2011): Protective Effect of Thymoquinone against D-Galactosamine-Induced Liver Injury in Rats. Australian Journal of Basic and Applied Sciences, 5, 49-58.

Mansour, M.A. (2000): Protective effects of thymoquinone and desferrioxamine against hepatotoxicity of carbon tetrachloride in mice. Life Sci., 66, 2583-2591.

McEwan, A.D., Fisher, E.W., Selman, I.E. and Penhale, W.J. (1970): A turbidity test for the estimation of immuneglobulin levels in neonatal calf serum. Clin. Chim. Acta., 27,155-163.

McGuire, T.C., Pfeiffer, N.E., Weikel, J.M. and Bartsch, R.C. (1976): Failure of cloistral immunoglobulin transfer in calves dying from infectious disease. JAVMA, 169, 713-718.

Nagi, M. and Mansour, M. (2000): Protective effect of thymoquinone against doxorubicin-induced cardiotoxicity in rats: a possible mechanism of protection. Pharmacol. Res., 41, 283-289.

Neishabouri, E.Z., Zuhair, M.H. and Seyed, N.O. (2004): Humoral and cellular immunomodulation induced by propoxure in $\mathrm{C} 57$ bl/6 Mice. J. Pharmaceut. Res., 3, 41-45.

Nelson, R.D., Quie, P.G. and Simmons, R.L. (1975): Chemotaxis under agarose: a new and simple method for measuring chemotaxis and spontaneous migration of human polymorphonuclear leukocytes and monocytes. J. Immunol., 115, 1650-1656.

Pfeiffer, N.E., McGuire, T.C., Bendel, R.B. and Weikel, J.M. (1977): Quantitation of bovine immunoglobulins: comparison of single radial immunodiffusion, zinc sulphate turbidity, serum electrophoresis and refractometer methods. Am. J. Vet. Res., 38, 693698.

Ragheb, A., Attia, A., Eldin, W.S., Elbarbry, F., Gazarin, S. and Shoker, A. (2009): The protective effect of thymoquinone, an anti-oxidant and anti-inflammatory agent, against renal injury: A review. Saudi J. Kidney Dis. Transpl., 20, 741-752.

Reitman, S. and Frankel, S. (1957): Alanine aminotransferse and Aspartate aminotransferse. Colourimeteric of serum transaminases. Am. J. Clin. Pathol., 28, 56.

Salem, M.L. (2005): Immunomodulatory and therapeutic properties of the Nigella sativa L. seed. Int. J. Immunopharmacol., 5, 17491770.

Sathiakumar, N., MacLennan, P.A., Mandel, J. and Delzell, E. (2011): A review of epidemiologic studies of triazine herbicides and cancer. Crit. Rev. Toxicol., 1, 1-34.

Satoh, K. (1978): Serum lipid peroxide in cerebrovascular disorders determined by a new colorimetric method. Clin. Chim. Acta., 90, 37-43.

Sayed-Ahmed, M.M., Aleisa, A.M., Al-Rejaie, S.S., Al-Yahya, A.A., Al-Shabanah, O.A., Hafez, M.M. and Nagi, M.N. (2010): Thymoquinone attenuates diethylnitrosamine induction of hepatic carcinogenesis through antioxidant signaling. Oxid. Med. Cell. Longev., 3, 254-261.

Schalm, O.W., Jaim, N.C. and Carroll E.J. (1975): Veterinary Haematology. $3^{\text {rd }}$ (Ed.) Lea. And Febiger, Philadelphia, U.S.A.

Tomizawa, M. and Casida, J.E. (2005): Neonicotinoid insecticide toxicology: mechanisms of selective action. Annu. Rev. Pharmacol. Toxicol., 45, 247-268.

Vouldoukis, I., Lacan, D., Kamate, C., Coste, P., Calenda, A. and 
Thymoquinone decreases immunotoxicity induced by imidacloprid insecticide

Mazier, D. (2004): Antioxidant and anti-inflammatory properties of a Cucumis melo LC. Extract rich in superoxide dismutase activity. J. Ethnopharmacol., 94, 67-75.

Ware, G.W., Whitacre, D.M. (2004): An Introduction to Insecticides, fourth ed., MeisterPro Information Resources, A division of Meister Media Worldwide, Willoughby, Ohio, USA.

Zhang, Y.T., Zheng, Q.S., Pan, J., Zheng, R.L. (2004): Oxidative damage of biomolecules in mouse liver induced by morphine and protected by antioxidants. Basic Clin. Pharmacol. Toxicol., 95, 53-58. 